\title{
Pré-natal masculino na estratégia saúde da família: Realidade ou utopia
}

\author{
Male pre-christmas in the family health strategy: Reality or utopia \\ Atención prenatal masculina em la estratégia de salud familiar: Realidade o utopia
}

\author{
Roberta Karlla Oliveira Guedes \\ ORCID: https://orcid.org/0000-0002-9922-0788 \\ Universidade Federal de Campina Grande, Brasil \\ E-mail: rkog92@gmail.com \\ Maria Clara Soares Dantas \\ ORCID: https://orcid.org/0000-0002-4206-7954 \\ Universidade Federal de Campina Grande, Brasil \\ E-mail: dantasclarinha@gmail.com \\ Egillane Madza Mendes Santa Cruz \\ ORCID: https://orcid.org/0000-0002-1864-0589 \\ Prefeitura Municipal de João Pessoa, Brasil \\ E-mail: egillane@hotmail.com \\ Tamares Marinho dos Santos \\ ORCID: https://orcid.org/0000-0001-9667-5245 \\ Prefeitura Municipal de Cuité, Brasil \\ E-mail: tamaresmarinho@hotmail.com \\ Luana Carla Santana Ribeiro \\ ORCID: https://orcid.org/0000-0003-3485-3100 \\ Universidade Federal de Campina Grande, Brasil \\ E-mail: luanacarlajp@hotmail.com \\ Jocelly de Araújo Ferreira \\ ORCID: https://orcid.org/0000-0003-2224-8499 \\ Universidade Federal da Paraíba, Brasil \\ E-mail: jocellyaferreira@hotmail.com
}

\begin{abstract}
Resumo
Avaliar a efetivação do pré-natal masculino na estratégia de saúde da família. Trata-se de um estudo exploratóriodescritivo, de natureza qualitativa, com profissionais médicos e enfermeiros da Estratégia Saúde da Família, do município de Cuité, estado da Paraíba, sendo a coleta do material empírico guiada por um roteiro semiestruturado, respeitando rigorosamente as normas da Resolução 466 de 12/12/2012, submetido e aprovado pelo Comitê de Ética e Pesquisa do Hospital Universitário Alcides Carneiro, sob o parecer $\mathrm{n}^{\circ}$ 3.176.135. Os dados foram analisados pela técnica de Análise de Conteúdo. Observou-se a partir do estudo que existe a implementação do pré-natal da gestante como preconiza o Ministério da Saúde, mas o pré-natal do parceiro, mesmo que preconizado e reconhecido por parte dos participantes como relevante na prática do serviço, ainda é realizado de forma pontual e subsidiado por outros programas. Com este estudo foi possível reconhecer a implantação e implementação do pré-natal masculino e identificou-se o conhecimento dos profissionais das USF acerca dele. Não obstante, constatou-se que as ações realizadas com os pais são limitadas necessitando da mulher para subsidiar a adesão desses homens ao pré-natal masculino.
\end{abstract}

Palavras-chave: Saúde do homem; Paternidade; Cuidado pré-natal; Saúde da família; Relações pai-filho.

\begin{abstract}
To evaluate the effectiveness of male prenatal care in the family health strategy. This is an exploratory - descriptive study, of a qualitative nature, with doctors and nurses from the Family Health Strategy, in the municipality of Cuite, state of Paraíba, with the collection of empirical material guided by a semi-structured script, strictly respecting the rules of Resolution 466 of 12/12/2012, submitted and approved by the Ethics and Research Committee of the Hospital Universitário Alcides Carneiro, under opinion No. 3,176,135. The data were formed using the Content Analysis technique. It was observed from the study that there is the implementation of the pregnant woman's prenatal care as recommended by the Ministry of Health, but the partner's prenatal care, even if recommended and recognized by the participants as relevant in the practice of the service, is still carried out in a timely manner and subsidized by other programs. With this study, it was possible to recognize the implantation and implementation of male prenatal care and the knowledge of USF professionals about it was identified. Nevertheless, it was found that the actions carried out with the parents are limited, requiring the woman to subsidize the adhesion of men to male prenatal care.
\end{abstract}

Keywords: Men's health; Paternity; Prenatal care; Family health; Father-son relations. 


\section{Resumen}

Evaluar la efectividad de la atención prenatal masculina en la estrategia de salud familiar. Se trata de un estudio exploratorio - descriptivo, de carácter cualitativo, con médicos y enfermeras de la Estrategia Salud de la Familia, en el municipio de Cuité, estado de Paraíba, con la recolección de material empírico guiado por un guión semiestructurado, estrictamente respetando las reglas de la Resolución 466 de 12/12/2012, sometida y aprobada por el Comité de Ética e Investigación del Hospital Universitário Alcides Carneiro, bajo dictamen No. 3.176.135. Los datos se formaron mediante la técnica de Análisis de contenido. Se observó del estudio que existe la implementación de la atención prenatal de la gestante recomendada por el Ministerio de Salud, pero la atención prenatal de la pareja, aunque recomendada y reconocida por las participantes como relevante en la práctica del servicio, sigue siendo realizados en forma oportuna y subvencionados por otros programas. Con este estudio se logró reconocer la implantación e implementación de la atención prenatal masculina y se identificó el conocimiento de los profesionales de la USF al respecto. Sin embargo, se encontró que las acciones realizadas con los padres son limitadas, requiriendo que la mujer subsidie la adhesión de los hombres a la atención prenatal masculina.

Palabras clave: Salud del Hombre; Paternidad; Cuidado prenatal; Salud de la familia; Relaciones padre-hijo.

\section{Introdução}

A partir das proposições deixadas pela Constituição Federal (CF) de 1988, o Brasil reconheceu que saúde é um direito de todos e dever do Estado, criando um sistema de saúde com princípios que assegurasse a todos um sistema universal, público, participativo, descentralizado e integral, que foi regulamentado pelas Leis 8.080/90 e 8.142/90. A primeira dispõe sobre conjunturas para promoção, proteção e recuperação da saúde, enquanto que a segunda dispõe sobre a participação da comunidade no sistema de saúde brasileiro (Santana, 2015; Brasil, 1990; Alburquerque, 2016).

Com a criação das Leis Orgânicas do Sistema Único de Saúde (SUS), que prezam por direitos de seus usuários, visualizava-se algumas negligências quando se tratava de públicos específicos, como o público masculino, e para diminuir essas lacunas, no ano de 2008 foi criada e aprovada a Política Nacional de Atenção Integral à Saúde do Homem (PNAISH), na qual os membros de diversos níveis hierárquicos governamentais passaram a reconhecer as necessidades desse público. A Política tem por objetivo auxiliar a qualidade de vida dos homens de 25 a 59 anos, e minimizar os agravos, a partir da garantia de acesso e acessibilidade para os serviços de saúde e dos princípios e diretrizes do SUS (Barbosa et al, 2019; Medeiros, 2013).

A relação entre o público masculino e as ações de saúde, principalmente com ênfase em gênero vem sendo bastante estudada ao longo dos últimos tempos a fim de desvelar e compreender como acontece essa influência em cima desses homens, o que vai afetar diretamente na saúde dessa população (Martins et al, 2020). O processo de transformação social, histórico, cultural e econômico vem influenciando diretamente no que diz respeito ao ato de cuidar dentro da saúde masculina, de tal forma essa temática passou a ser abordada de maneira cada vez mais frequente enfatizando a importância de valorizar questões referentes a gênero e masculinidade garantindo a esse público seus direitos frente a sociedade e ao SUS (Rocha, Martins, Spindola, Costa, Alves, Moraes, 2020).

A PNAISH buscando estabelecer boa condição de vida da população masculina enfatiza através de eixos e diretrizes ações que vão garantir aos homens promoção de saúde e prevenção de agravos, dentre estes os direitos sexuais e reprodutivos que é a paternidade e o cuidado. A paternidade designa-se como a iniciativa para o homem adentrar ao serviço de saúde e para que ele possa acompanhar todo o processo gestacional, criando mais vínculo com o filho, como o já existente binômio mãefilho. Esse eixo, desta política ficou conhecido como pré-natal masculino, em que a equipe de saúde vai aproveitar a presença desse pai para ofertar serviços como consultas, exames de rotina, testes rápidos, atualização de carteira de vacina e ações de educação em saúde, propiciando a esse homem um preparo para que ele possa exercer a paternidade com compromisso (Silva, 2019).

Dentre os direitos garantidos à população masculina, estão os direitos sexuais e reprodutivos, que tratam de paternidade e cuidado, garantindo ao homem o acompanhamento do processo gestacional da parceira, facilitando a criação do 
vínculo entre o binômio mãe e filho e o parceiro enquanto pai, por intermédio de ações como consultas, exames de rotina, testes rápidos, atualização de carteira de vacina e ações de educação em saúde, propiciando a esse homem um preparo para que ele possa exercer a paternidade com compromisso, originário da confirmação da gestação da parceira, levando ao acompanhamento do casal grávido (Mendes \& Santos, 2019).

Para a comunidade científica, o campo da pesquisa no tocante à saúde do homem e suas vertentes é relevante por ser um conteúdo ainda pouco explorado, percebendo-se escassez na literatura científica. Assim, aponta-se uma necessidade de busca pelo conhecimento sobre o pré-natal masculino. No plano da ciência do cuidar, a temática remete ao reconhecimento do que é pré-natal do parceiro e sua importância, garantindo ao homem seus direitos enquanto cidadãos e pai, de forma a fortalecer vínculos entre profissional, parceiro e o binômio mãe-filho.

Para a sociedade, o pré-natal masculino por ser algo ainda recente e inovador, pode deixar dúvidas sobre sua real importância, principalmente para os profissionais de saúde que, em detrimento das dificuldades de atrair o público masculino para as unidades básicas, apresentam resistência em implementar as ações para essa população.

Mediante a contextualização sobre a concepção e relevância do pré-natal masculino, surge a seguinte indagação: os profissionais da Estratégia de Saúde da Família (ESF) estão implementando de forma efetiva o pré-natal do parceiro, nas atividades rotineiras do serviço?

A fim de responder a estas inquietações, esta pesquisa objetiva em linhas gerais: avaliar a efetivação do pré-natal masculino na ESF. E de maneira específica, objetiva: averiguar a ocorrência da implantação e implementação do programa de pré-natal masculino nas Unidades Saúde da Família (USF); identificar o conhecimento dos profissionais enfermeiros e médicos a respeito do pré-natal masculino nas USF; e descrever os determinantes que dificultam e facilitam a efetivação do pré-natal masculino nestas unidades.

\section{Metodologia}

Tratar-se-á de um estudo exploratório - descritivo, de natureza qualitativa. Segundo Gil (2008) a pesquisa exploratória tem por objetivo trazer ao pesquisador conhecimentos suficientes para que ele, depois conhecer todo o assunto possa construir suas hipóteses acerca do objeto pesquisado. Em relação ao estudo descritivo, o autor supracitado refere que este tipo de estudo tem por finalidade descrever determinada população, situação ou fenômeno, ao determinar relações entre variáveis.

O delineamento qualitativo da pesquisa basear-se-á em um método científico que vai estar atrelada ao levantamento de dados não quantificados, a fim de compreender determinado comportamento, opinião de expectativa de determinada amostra, de forma que se chegue a uma decisão correta para a questão-problema que envolve a pesquisa (Taquette; Minayo, 2016).

Estudo realizado no município de Cuité-Paraíba, o qual possui cobertura total em termos de serviços de saúde básica, contando com seis USF, cenário de desenvolvimento deste estudo. O universo populacional dessa pesquisa foi composto pelos médicos e enfermeiros das USF e para a delimitação da amostragem empírica utilizou-se o parâmetro da conveniência.

Mediante a população amostral foram adotados os seguintes critérios de inclusão: profissionais regulamentados pelo conselho da profissão, com jurisprudência na Paraíba, lotados profissionalmente nas USF; que possuem vínculo empregatício (regime celetista, contrato ou concurso) com a Secretaria Municipal de Saúde (SMS) de Cuité; e que estavam em atividade profissional no período da coleta do material empírico.

Ainda, desta população, foram excluídos os participantes que estivessem de férias, licença saúde, licença maternidade ou afastamento para capacitação profissional. 
Após a adoção dos critérios estabelecidos nesse estudo, a amostra empírica ficou composta por seis (6) participantes, sendo quatro (4) enfermeiros e dois (2) médicos. É imperioso destacar que esses participantes corresponderam a $66,7 \%$ da população, por considerar que três (3) USF não possuíam profissionais médicos e três (3) profissionais não aceitaram participar deste estudo.

Os dados foram coletados por meio de uma entrevista conduzida por um roteiro semiestruturado desenvolvido pela pesquisadora, composto por perguntas discursivas, permitindo a caracterização dos profissionais médicos e enfermeiros que atuavam junto ao programa de pré-natal masculino nas USF, abordando os conhecimentos e as percepções desses profissionais acerca do programa, enfatizando as potencialidades, as dificuldades e como ocorre essa implementação nas unidades. Como instrumento secundário utilizou-se o diário de campo, a fim de que a pesquisadora descreva informações não verbalizadas durante as entrevistas.

As falas foram transcritas conforme as convenções do padrão de Marcuschi e analisadas segundo o método analítico da Análise de Conteúdo, na modalidade temática, que analisa a comunicação verbal e não verbal seguindo três etapas: préanálise, exploração do material e tratamento dos resultados que envolvem a inferência e a interpretação.

Com a finalidade de garantir o anonimato dos participantes, atribuiu-se codificações alfanuméricas para cada um deles. A pesquisa se desenvolveu seguindo a legislação do Conselho Nacional em Saúde (CNS), por meio da Resolução 466 de 12 de dezembro de 2012, que estabelece a necessidade da existência de um Termo de Consentimento Livre e Esclarecido, assinado pelo participante e a submissão deste estudo ao Comitê de Ética e Pesquisa do Hospital Universitário Alcides Carneiro (HUAC), sob parecer $\mathrm{n}^{\circ}$ 3.176.135.

Este estudo apresentou riscos mínimos aos participantes, como o possível constrangimento por serem entrevistados sobre sua atividade de assistência ao pré-natal, sendo estes riscos minimizados na medida em que se ofertou diálogo prévio, criando e fortalecendo vínculos antes de entrevistar os participantes. Quanto aos benefícios, refere-se as importantes contribuições para ciência, haja vista a escassez de conhecimentos nessa perspectiva; sendo assim, este estudo poderá contribuir para melhorar a assistência do "Programa de pré-natal masculino" de forma que se obtenha eficácia na implementação do programa. 


\section{Resultados}

Tabela 1. Distribuição absoluta das características dos participantes da pesquisa, Cuité (PB), mar./abr. de 2019.

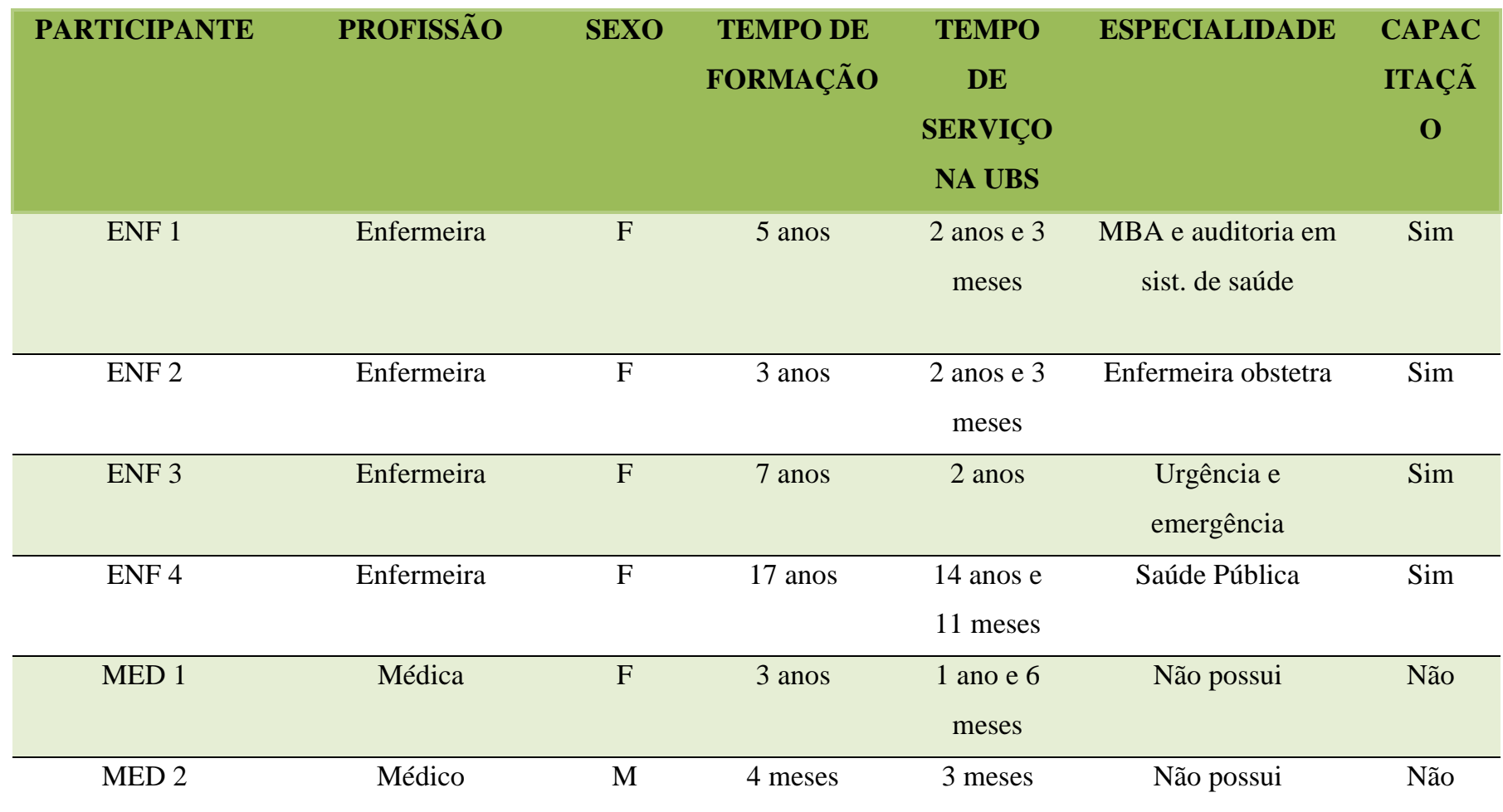

Fonte: Dados da pesquisa (2019).

Tabela 2. Distribuição absoluta e percentual dos núcleos de sentido da Categoria I. Cuité (PB), mar./abr. de 2019.

\begin{tabular}{c|cc}
\hline Núcleos de sentido & $\mathbf{N}^{\mathbf{0}}$ absoluto & $\%$ \\
\hline Feminino & 6 & $8 \%$ \\
\hline Parceiro & 5 & $12 \%$ \\
\hline Pré-natal & 10 & $6 \%$ \\
\hline Praticamos & 5 & $18 \%$ \\
\hline Consulta & 15 & $6 \%$ \\
\hline Gestação & 5 & $4 \%$ \\
\hline Comunicação & 3 & $4 \%$ \\
\hline Queixas & 3 & $12 \%$ \\
\hline Exames & 3 & $12 \%$ \\
\hline Agendado & 10 & $12 \%$ \\
\hline Convocar & 10 & $100 \%$ \\
\hline Total & 82 & $6 \%$ \\
\hline
\end{tabular}

Fonte: Dados da pesquisa (2019). 
Tabela 3. Distribuição absoluta e percentual dos núcleos de sentido da Categoria II. Cuité (PB), mar./abr. de 2019.

\begin{tabular}{c|cc}
\hline Núcleos de sentido & $\mathbf{N}^{\mathbf{0}}$ absoluto & $\%$ \\
\hline Participação & 9 & $26 \%$ \\
\hline Homem & 15 & $44 \%$ \\
\hline Ativa & 3 & $9 \%$ \\
\hline Saúde & 3 & $9 \%$ \\
\hline Pai & 4 & $12 \%$ \\
\hline Total & 34 & $100 \%$ \\
\hline
\end{tabular}

Fonte: Dados da pesquisa (2019).

Tabela 4. Distribuição absoluta e percentual dos núcleos de sentido da Categoria III. Cuité (PB), mar./abr. de 2019.

\begin{tabular}{|c|cc}
\hline Núcleos de sentido & $\mathbf{N}^{\mathbf{0}}$ absoluto & $\%$ \\
\hline Trabalho & 7 & $17 \%$ \\
\hline Horário & 5 & $12 \%$ \\
\hline Dificulta & 3 & $7 \%$ \\
\hline Homem & 8 & $19 \%$ \\
\hline Reforço & 3 & $7 \%$ \\
\hline Parceiro & 4 & $9 \%$ \\
\hline Convocar & 3 & $9 \%$ \\
\hline Mulher & 4 & $12 \%$ \\
\hline Profissional & 5 & $100 \%$ \\
\hline Total & 42 & $7 \%$ \\
\hline
\end{tabular}

Fonte: Dados da pesquisa (2019).

O perfil dos participantes do estudo foi composto predominantemente por profissionais enfermeiros do sexo feminino, com tempo de formação entre 3 e 5 anos, havendo apenas duas exceções em que uma enfermeira possui tempo de formação acima de 15 anos e um médico com tempo de formação inferior a um (01) ano, em que a maioria desses profissionais eram capacitados na temática e possuíam alguma especialidade, sendo relevante mostrar que apenas um (01) desses apresenta especialização em saúde pública.

A partir da disposição dos núcleos de sentido da Tabela 2, pode-se identificar a predominância de determinados termos como: "pré-natal", "agendado" e "convocar", que se apresentaram 10 vezes, totalizando um percentual de $12 \%$ cada; "consulta" que se apresentou 15 vezes, totalizando um percentual de 18\%. Todos esses termos foram identificados a partir das falas dos participantes.

Com base na Tabela 3, analisou-se a existência de dois (02) núcleos de sentido predominantes, sendo eles: participação (09) citações, totalizando um percentual de $26 \%$ e homem (15) citações, totalizando um percentual de $44 \%$. Destaca-se que estes termos foram identificados nas falas dos participantes.

A partir do exposto na Tabela 4, pode-se identificar os seguintes núcleos de sentido predominantes nos trechos dos discursos dos participantes: trabalho (07) citações, totalizando um percentual de 7\%; homem (08) citações, totalizando um percentual de $19 \%$ e profissional (05) citações, totalizando um percentual de $12 \%$. 
Após a análise dos dados expostos nas Tabelas 2,3 e 4, foram criadas três categorias e dentro da primeira e da terceira, emergiram duas subcategorias, descritas a seguir.

\section{Categoria I - A implementação do programa de pré-natal: uma realidade garantida pelo SUS}

As falas dos participantes evidenciam a existência do programa de pré-natal, independente se masculino ou feminino; todavia, as subcategorias clarificarão a que pré-natal os participantes deste estudo estão se remetendo. Segue, os excertos das falas que versam sobre a implementação do programa de pré-natal:

[...] o pré-natal já existe há trilhões de anos né? Faz parte do nosso cronograma de atendimento [...]. (ENF 1)

[...] pré-natal feminino, sim! [...]. (MED 1)

Subcategoria I - Pré-natal feminino: o universo seguido.

[...] faz parte do nosso cronograma de atendimento, sempre eu

atendo gestantes na quarta de manhã e a tarde e faço as consultas de rotina, né?[...]. (ENF 1)

[...] pré-natal normal e pré-natal do parceiro [...]. (ENF 4)

Subcategoria II - O pré-natal no universo masculino: um projeto ainda em construção.

[...] se o parceiro não for junto, né? Com a mulher a gente faz esse reforço pedindo a mulher com que ela faça com que esse parceiro venha também e seja incluso nesse pré-natal [...]. (ENF 2)

[...] ]o pré-natal masculino não é agendado porque geralmente a gente faz em conjunto, a gente agenda o da mulher e já pede pra ela trazer o parceiro [...]. (ENF3)

Categoria II - O conhecimento teórico sobre o pré-natal masculino: contribuição para efetivação na práxis.

[...] seria uma participação mais ativa, que na realidade já tem esse conceito de que seria só por parte da mulher, mas a gente precisa incluir os homens e aproveita essa oportunidade pra também tá cuidando da saúde do homem “[...]. (MED 2)

Categoria III - Os determinantes para a (não) efetivação do pré-natal masculino.

Subcategoria I - As dificuldades para a não efetivação do pré-natal masculino.

Além do participante MED1, outros relataram algumas dificuldades para efetivação do pré-natal do parceiro, citando a inadequação entre a realização do pré-natal masculino com a jornada de trabalho e o horário de atendimento das USF.

[...] porque o que dificulta muito é a carga horária de trabalho desses homens, né? [...] (ENF 2).

[...] pela falta de tempo, pela maioria dos homens trabalharem fora [...] (MED 2).

Subcategoria II- As facilidades para efetivação do pré-natal do parceiro.

[...] tem uns que participam do início até o final da gestação, então é super tranquilo, mas não conseguimos a adesão de $100 \%$ [...] (ENF3) 


\section{Discussão}

O período gestacional caracteriza-se por inúmeras mudanças físicas e emocionais para a gestante e para os que a rodeiam. Cada gestante e sua família possuem peculiaridades que acarretam em dúvidas, medos e curiosidades sobre a gestante e o bebê. Profissionais da atenção básica, ao executarem o programa de pré-natal, realizam ações que beneficiam a mãe e o filho, no intuito de promover uma assistência de qualidade.

Por meio das falas da Subcategoria II (Categoria I), nota-se que o pré-natal feminino é de fato rotina do serviço há muito tempo e é realizado a partir da confirmação através de exames laboratoriais e avaliação dos profissionais médicos e enfermeiros; enquanto que o pré-natal do parceiro, mesmo preconizado pelo MS, ainda é realizado de forma pontual na ESF.

As falas dos participantes deste estudo enfatizam a existência do pré-natal, porém a ocorrência do mesmo está sempre atrelada à presença da mulher, mostrando que o pré-natal masculino se configura de maneira minimizada. Essa diminuta participação masculina no pré-natal foi justificada pelos participantes pela pouca adesão masculina às USF, mesmo eles sabendo da existência de políticas e programas que os amparam.

A partir da exposição das falas contidas na Subcategoria I (Categoria III), compreende-se que os impedimentos para o homem procurar o serviço de saúde vão além das questões culturais, pois fatores como horário de funcionamento das unidades e jornada de trabalho do público acabam impossibilitando essa acessibilidade.

O homem traz consigo a responsabilidade de provedor, papel prioritário e atribuído a ele historicamente, por possibilitar o cumprimento de suas obrigações. O público masculino demonstra desinteresse quando se trata de cuidar da saúde por diversos motivos, dentre os principais a questão cultural, a falta de tempo e ainda uma percepção de que são invulneráveis a patologias (Pereira; Araújo; Dantas, 2018).

O pré-natal masculino proporciona a realização de atendimentos e orientações diversas, igualmente como acontece durante o pré-natal com a mulher, reforçando a importância da saúde masculina e da participação do homem, enquanto homem saudável, parceiro e pai. Para assegurar ao homem seus direitos enquanto parceiro e pai, a Lei nº 11.108 , de 7 de abril de 2005 , foi sancionada determinando que a gestante possua um acompanhante durante todo período de trabalho de parto, parto e pósparto, na rede pública e privada de saúde e independente do procedimento ser normal ou cesariana (Brasil, 2005).

Também destaca-se como ganhos para o homem e pai, algumas leis que garantem o direito dele de: ausentar-se do trabalho por até dois dias para acompanhar a mulher nas consultas e exames médicos durante a gravidez; a ampliação da licença paternidade de 5 para 20 dias corridos de afastamento de suas atividades para assistência ao seu filho recém-nascido; ausentar-se de suas atividades enquanto trabalhador para acompanhar a criança ao médico uma vez ao ano durante os primeiros 72 meses de vida, independente do filho ser biológico ou adotivo (Hermann; Silva; Chakora; Lima, 2016).

Mesmo diante de tantas conquistas, esta pesquisa demonstra por meio das falas contidas na Subcategoria II (Categoria III), a falta de interesse do homem na realização desse pré-natal, a parceira é estimulada a convocá-lo de forma que garanta a esse homem, enquanto parceiro e pai, o usufruto de seus direitos de saúde e sua participação no momento gestacional de sua parceira, de maneira efetiva cuidando da saúde e construindo e fortalecendo vínculos entre pai-mãe-bebê.

Os participantes do estudo foram em sua maioria recém-formados e alguns com capacitação e/ou qualificação na área, tendo, portanto, breve conhecimento sobre pré-natal masculino, como referido na Categoria II.

A existência do conhecimento teórico sobre o programa por parte dos profissionais foi visualizada nas falas dos participantes na Categoria II; contudo, deixaram evidente por meio dos seus discursos, na Categoria I, que a adesão do público masculino ao programa ainda está associada a outros programas como aqueles referentes à saúde da mulher, a exemplo do prénatal feminino. Ainda ao analisar as falas dos profissionais que participaram do estudo, compreende-se que o pré-natal masculino apesar de ser conhecido teoricamente, não é um programa implementado dentro da rotina do serviço de saúde. 
É de extrema importância que haja entendimento por parte do parceiro que o período gestacional não é um momento que deva ser vivenciado apenas pelas mulheres (Cardoso; Junior; Bonatti; Santos; Ribeiro, 2018). Quando o homem e a mulher se sentem grávidos e participam conjuntamente do pré-natal, visualiza-se a minimização da desigualdade entre eles e favorece uma paternidade ativa, como foi normatizada pelo MS desde 2011.

Dessa forma, o MS utilizou o pré-natal do parceiro como forma de incluir estes homens no eixo de paternidade e cuidado que possuem ações voltadas ao planejamento reprodutivo. Para tanto, ações dentro do pré-natal masculino são ofertadas para garantir a atenção de forma integral a esse homem enquanto parceiro e pai. Dentre estas ações estão: o acolhimento do parceiro; a vinculação deste homem na unidade e em seguida ao programa de pré-natal masculino; a oferta de testes rápidos; a atualização do cartão de vacinação; a realização das consultas de rotina e exames, serviços de referenciamento e contrarreferenciamentos, bem como o incentivo a participação desse homem em ações de educação e saúde (Hermann; Silva; Chakora; Lima, 2016).

É imperioso destacar que neste estudo, o não conhecimento teórico a respeito do pré-natal do parceiro, se fez presente por parte de alguns participantes. Acredita-se que o fato se deve a uma lacuna enquanto formação profissional, em que o profissional médico ainda é formado e atua sob o modelo biomédico, enfatizando o indivíduo de forma intervencionista e não de maneira holística.

Percebe-se que a própria formação profissional se transforma em uma dificuldade para a efetivação do pré-natal masculino, nas USF. Na Categoria III foram abordadas algumas dessas dificuldades e facilidades para a efetivação deste programa de pré-natal.

Um maior número de homens tem seu trabalho realizado nos turnos matutino e vespertino, tornando difícil o acesso destes ao serviço de saúde e a realização de ações de prevenção de doenças e promoção de saúde, dentre estas ações está a do pré-natal masculino, em que os homens, muitas vezes, não se sentem responsabilizados.

São numerosos os motivos que causam dificuldades para a adesão do homem nas USF, o que diminui a participação ativa deste homem durante o período gestacional. Em alguns casos, o sentimento de paternidade ocorre somente após o nascimento, uma vez que os homens não passam por modificações externas no seu corpo, o que não os caracterizam para esta fase, como ocorre na mulher (Balica \& Aguiar, 2019).

A ausência dos homens no pré-natal, durante as consultas e ações, pode ser atenuada, caso eles possuíssem contabilidade e mesmo disponibilidade em relação ao seu horário de trabalho e o pré-natal (Henz; Medeiros; Salvadori, 2017). Esta condição, pode ser considerada um forte impeditivo, já que as unidades funcionam em horário comercial, ficando incompatível com o horário que os homens dispõem, sendo necessário que haja um atendimento ampliado para esse público (Cordeiro; Fontes; Fonseca; Barboza; Cordeiro, 2014).

Não se pode falar apenas das dificuldades, pois os participantes do estudo demonstraram na Categoria II que possuem conhecimento a respeito do pré-natal masculino, e que tentam implementá-lo na USF, mesmo que de maneira efêmera.

As facilidades foram poucas, considerando que o pré-natal masculino ainda permeia um universo teórico e com práticas pontuais, como dito na Categoria II. Como facilidades, foram ressaltadas a comunicação e a consolidação prática do pré-natal firmado na figura da mulher e mãe, como descrito na Categoria I.

A comunicação é uma ferramenta natural e própria do ser humano, que tem por finalidade realizar a troca de percepções sobre as ações práticas do cotidiano, podendo ser considerada um dos maiores facilitadores para a realização de ações em saúde. Na Enfermagem essa comunicação vai possibilitar a promoção de relacionamento entre pacientes e profissionais, entre profissionais e familiares e entre componentes da equipe multiprofissional de saúde (Ferreira, 2011). Sendo assim, porque não compartilhar esse instrumento para auxiliar na efetivação do pré-natal do parceiro? 
O Programa de pré-natal é realizado de forma rotineira nas USF. Entretanto, ao visualizar este programa, logo submete-se a imagem da mãe. Onde fica o parceiro e o sobretudo pai? Na Subcategoria II (Categoria I) os participantes do estudo falaram que para ações pontuais de pré-natal em que o pai se faz presente, é necessário que a parceira os leve ao serviço de saúde, seja a partir de um chamado profissional com o propósito de realizar o pré-natal ou pela convocação a partir da parceira, que demonstra desejo na participação do homem como parceiro e pai.

Mediante a primeira consulta do pré-natal realizada após a confirmação da gestação, ressalta-se a importância para o momento que será vivenciado pela mulher a partir daquele instante. Para que a gestante se sinta acolhida é imprescindível que exista a boa qualidade do serviço, proporcionando-lhe atenção integral e holística de acordo com suas necessidades.

Uma assistência qualificada é aquela que possui ações que integrem uma rede de atenção adequada, que oferte à gestante promoção de saúde, prevenção de agravos e doenças, além da assistência nos mais diversos níveis de atenção (Silva; Alvez; Rodrigues; Vieira; Marchiori, Santos, 2018).

\section{Considerações Finais}

Com este dado estudo foi possível visualizar e reconhecer os meios e métodos que viabilizaram a implementação do pré-natal masculino, bem como a identificação do nível de conhecimento dos profissionais atuantes das USF acerca deste tema; contudo, revelou-se uma lacuna na formação do profissional médico. Ainda, observou-se que quando o pré-natal masculino é aplicado no cotidiano das unidades, ele ocorre de maneira pontual e atrelado a outros programas do MS, isto é consequência da cultura da própria sociedade ao mostrar que o homem tem características patriarcais e hegemônicas, necessitando do papel feminino para subsidiar a adesão e introdução desses ao pré-natal masculino.

A partir dos resultados encontrados, este estudo poderá contribuir para novas pesquisas que investiguem as ações que são desenvolvidas no pré-natal masculino nas USF, servindo de base para programas de educação continuada com os profissionais, novas ações e determinantes a nível das políticas de saúde pública, promovendo várias discussões e construção de extensões universitárias na graduação de médicos e enfermeiros.

Sendo assim, sugere-se que novos estudos sejam desenvolvidos acerca do pré-natal masculino diante USF, visto sua importante implementação contribuindo na integralidade, humanização e visão holística da assistência prestada.

\section{Referências}

Alburquerque, M. I. N. (2015). Uma revisão sobre as políticas públicas de saúde no Brasil. Recife: [s.n.], 33 p. <https://ares.unasus.gov.br/acervo/html/ARES/3333/1/2saud_socie_polit_public_saud_2016.pdf>.

Balica, L. O. \& Aguiar, R. S. (2019) Percepções paternas no acompanhamento do pré-natal. Revista de Atenção à Saúde, v. 17, n. 61. < file://C:/Users/Karlla\%20Guedes/Downloads/5934-Texto\%20do\%20Artigo-19922-1-10-20191209.pdf>

Barbosa, Y. O., Menezes, L. P. L., Santos, J. M. J., Cunha, J. O., Albuquerque, T. I. P., Araújo, D. C. et al. (2019). Factors associated with reasons for men not seeking Primary Health Care services. <https://www.revistamundodasaude.com.br/uploads/20190100.PDF>. DOI: 10.15343/0104-7809.20194303666679.

Brasil, Lei n: 11.108, de 7 de abril de 2005. Altera a Lei n. 8.080, de 19 de setembro de 1990, para garantir às parturientes o direito à presença de acompanhante durante o trabalho de parto, parto e pós-parto imediato, no âmbito do Sistema Único de Saúde-SUS. Diário Oficial da União, 2005. <http://www.planalto.gov.br/ccivil_03/_ato2004-2006/2005/lei/111108.htm>.

Brasil, Lei no 8.142 de 28 de dezembro de 1990. Dispõe sobre a participação da comunidade na gestão do Sistema Único de Saúde (SUS) e sobre as transferências intergovernamentais de recursos financeiros na área da saúde e dá outras providências. Diário Oficial da União, Brasília, 21 set. 1990. <http://www.planalto.gov.br/ccivil_03/leis/18142.htm>.

Participation in the Prenatal Routine Under the Perspective of Pregnant Women. Journal of Research: Care is Fundamental, p. 856-862. <file:///C:/Users/danta/Downloads/The_Partners_Involvement_in_the_Prenatal_Routine_.pdf>.DOI:10.9789/2175-5361.2018.v10i3.856-862.

Cordeiro, S. V. L., Fontes, W. D., Fonseca, R. L. S., Barboza, T. M. \& Cordeiro, C. A. (2014). Atenção básica à saúde masculina: possibilidades e limites no atendimento noturno. Escola Anna Nery Revista de Enfermagem, v. 18, n. 4, p. 644-649. <https://www.scielo.br/pdf/ean/v18n4/1414-8145-ean-18-040644.pdf>. DOI: 10.5935/1414-8145.20140091. 
Research, Society and Development, v. 10, n. 7, e6010716235, 2021 (CC BY 4.0) | ISSN 2525-3409 | DOI: http://dx.doi.org/10.33448/rsd-v10i7.16235

Ferreira, J. A. (2011). Comunicação dos enfermeiros com usuários do gênero masculino: um estudo representacional. Dissertação de Mestrado. Universidade Federal do Rio Grande do Norte. <https://repositorio.ufrn.br/jspui/bitstream/123456789/14727/1/JocellyAF_DISSERT.pdf>.

GIL, A. C. (2008) Métodos e técnicas de pesquisa social. 6. ed. São Paulo: Editora Atlas.

Henz, G. S., Medeiros, C. R. G. \& Salvadori, M. (2017). The parental inclusion during prenatal care. Journal of Nursing and Health Care, v. 6, n. 1. <file://C:/Users/danta/Downloads/2053-11769-2-PB.pdf>. DOI: https://doi.org/10.18554/reas.v6i1.2053.

Hermann, A., Silva, M. L., Chakora, E. S. \& Lima, D. C. (2016). Guia do pré-natal do parceiro para profissionais de saúde. Rio de Janeiro: Ministério da Saúde,:〈https://portalarquivos2.saude.gov.br/images/pdf/2016/agosto/11/guia_PreNatal.pdf>.

Martins, E. R. C. et al. Ações extensionistas para a saúde do homem: um relato de experiência. Research, Society and Development, v. 9, n. 11, p. e1579119687-e1579119687, 2020. : < https://rsdjournal.org/index.php/rsd/article/view/9687/8635>

Medeiros, R.L.S.F.M. (2013). Dificuldades e estratégias de inserção do homem na atenção básica à saúde: a fala dos enfermeiros. <https://repositorio.ufpb.br/jspui/bitstream/tede/5133/1/arquivototal.pdf>.

Mendes, S. \& Santos, K. C. (2019) Pré-natal masculino: a importância da participação do pai nas consultas de pré-natal. Enciclopédia biosfera, v. 16, n. 29.

Pereira, S.W., Araújo, F.J. \& Dantas, F.F.B. (2018) The Implications Of The Paternity Process For Male Behavior. Journal of Primary Attention to Health, v. 21, n. 2 .

Rocha, F. C. S. et al. Acolhimento da população masculina sob a percepção dos profissionais de enfermagem: desconstrução da invisibilidade. Research, Society and Development, v. 9, n. 12, p. e6791210708-e6791210708, 2020. < https://rsdjournal.org/index.php/rsd/article/view/10708/9668>

Santana, M. N. S. (2015). Controle social na política saúde: um estudo sobre o município de Ilhéus.

Silva, Michelle Leite da. (2019) A paternidade em rede: subsídios para o exercício da paternidade ativa dos pais/parceiros com base na Pesquisa Nacional

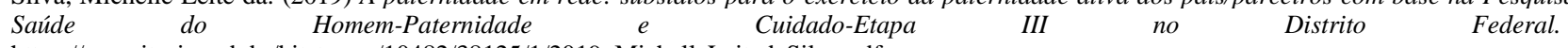
https://repositorio.unb.br/bitstream/10482/38125/1/2019_MichelleLeitedaSilva.pdf>

Silva, L. A., Alves, V. H., Rodrigues, D. P., Vieira, B. D. G., Marchiori, G. R. S. \& Santos, M. V. (2018). A humanização do cuidado pré-natal na perspectiva valorativa das mulheres gestantes. Revista de Pesquisa: Cuidado é Fundamental, p. 1014-1019. <http://www.seer.unirio.br/index.php/cuidadofundamental/article/view/6302/pdf>. DOI: 10.9789/2175-5361.2018.v10i4.1014-101.

Taquette, S. R. \& Minayo, M. C. (2016). Análise de estudos qualitativos conduzidos por médicos publicados em periódicos científicos brasileiros entre 2004 e 2013. Physis: Revista de Saúde Coletiva, v. 26, n. 2, p. 417-434. 